\title{
Impacts of Northern Expansion of Typical Corn Planting Regions in China under the Background of Climate Warming and Spatial Evolution of Cold Damage
}

\author{
Jing Zhao ${ }^{1}$, Jiquan Zhang ${ }^{1, *}$, Xingpeng $\mathrm{Liu}^{1}$, Ying $\mathrm{Li}^{2}$, Rui Wang ${ }^{1}$ \\ 1Northeast Normal University College of Environmental Science, Changchun, 130024, China \\ 2 Liaoning Normal University of Urban Planning and Environment Science, Dalian 116029, China \\ 气候变暖背景下中国典型玉米种植区北扩影响

\section{及冷害空间演变规律} \\ 赵静 ${ }^{1}$, 张继权 ${ }^{1, *}$, 刘兴朋 ${ }^{1}$, 李颖 ${ }^{2}$,王㥯 ${ }^{1}$ \\ 1 东北师范大学环境学院, 长春 130024 , 中国 \\ 2 辽宁师范大学城市与环境学院, 大连 116029 , 中国
}

\begin{abstract}
Global warming has caused geographical displacements in the north of the safe corn planting in the Northeast, and the occurrence of cold damage in sensitive areas after the north boundary displacement has yet to be explored. Based on the effective accumulated temperature required for the growth and development of different maize varieties in Northeast China, combining with indicators of corn chilling injury in different growth stages, the changes in suitable areas for maize planting in Northeast China and the occurrence frequency of cold damage in sensitive areas were revealed, and the index conducts trend was analysed.The results show that the safety boundary of corn planting has been continuously moving
\end{abstract}

*通讯作者: 张继权 (1965-), 教授, 博士 生导师, 主要从事环境灾害风险评价与管理、 预警等方向研究

邮箱: Zhangjq022@nenu.edu.cn northwards in the past 30 years, and early maturing varieties have gradually been replaced by medium-maturing varieties; in the context of global warming, the frequency of chilling damage in most regions of Northeast China showed a downward trend, and the cold damage intensity showed a downward trend. The decline is significant, but it does not rule out the extreme cold damage in the region. Therefore, the spatial evolution rules of northern expansion and cold damage of maize planting areas under the background of climate warming were explored, which provided reference for the rational distribution of corn and prevention of cold damage in Northeast China.

Keywords:Cold damage;Corn planting areas;Spatial variation; Climate change.

摘要

全球气候变暖导致东北地区玉米安全种 植北界发生地理位移, 北界位移后界限变化 
敏感区冷害发生情况亟待探讨。研究基于东 北地区不同品种玉米生长发育期所需的有 效积温出发, 结合各生长阶段玉米冷害判识 指标, 揭示了气候变化背景下东北玉米种植 适宜区变化情况及敏感区冷害发生频率, 并 对冷害指数进行趋势分析。结果表明过去 30 年玉米安全种植界线不断北移, 早熟品种逐 渐被中熟品种替代; 全球气候变暖背景下, 东北大部分地区冷害频率呈现下降趋势, 冷 害强度下降显著, 但不排除区域极端冷害的 发生。因此探究气候变暖背景下玉米种植区 北扩及冷害空间演变规律, 为东北地区玉米 合理布局及冷害防治提供参考。

关键字: 低温冷害; 玉米种植区; 空间变化 规律; 气候变化

\section{1. 引言}

气候变化是近几十年来学术界研究的热 点问题。全球气候变暖加剧导致中高纬度地 区热量增加, 作物种植制度界限、作物布局 及生育期等发生变化 ${ }^{[1-3]}$ 。玉米作为喜温植物, 对热量条件的要求相对较高。我国典型玉米 种植区主要包括东北春玉米区、黄淮海夏玉
80 年代以来, 玉米种植区北界从松嫩平原南 部地区逐渐向北扩展到伊春和大兴安岭地 区, 北移了 4 个纬度 ${ }^{[4]}$ 。气候波动性增加导 致玉米安全种植北界地理位移后的敏感区 的农业灾害风险增加, 区域性阶段性冷害时 有发生, 造成损失加剧 ${ }^{[5-6]}$ 。研究基于玉米生 长期 $\geqslant 10^{\circ} \mathrm{C}$ 活动积温指标划分 1980 年代、 1990 年代、2000 年代东北地区不同品种玉 米种植区域, 结合玉米生长发育特性采用热 量指数距平百分率作为冷害判识依据, 明确 年代间安全种植界限变动敏感区内冷害发 生频率的变化趋势, 为玉米种植合理布局及 冷害防治提供理论参考。

\section{2. 资料与方法}

\section{1 资料来源及处理}

研究收集了东北三省 53 个基本气象站 点 1980-2010 年逐日平均气温和 48 个农业 气象站点春玉米物候期数据 (图 1), 资料来 源于中国气象局信息中心。依据东北地区不 同品种玉米 $\geqslant 10^{\circ} \mathrm{C}$ 活动积温指标将玉米种 植区划分 6 种类型 ${ }^{[7]}$ (表 1)。利用 ArcGIS 的反距离权重方法 (IDW) 进行空间插值,

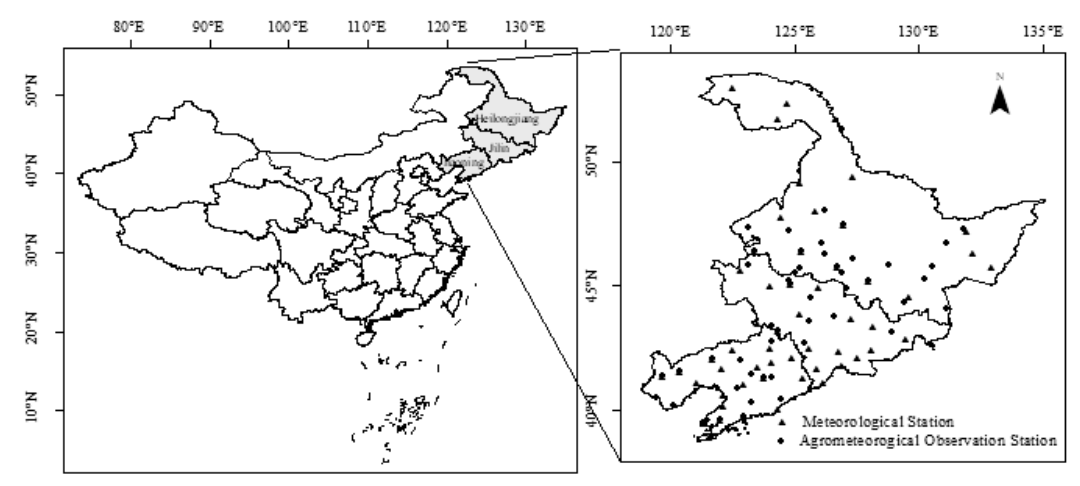

图 1 研究区概况

米区和西南玉米区。随着气候变暖, 我国玉

获得要素的空间分布图。

米种植界限已发生显著的推移, 自 20 世纪

表 1 东北地区不同品种区玉米 $\geqslant 10^{\circ} \mathrm{C}$ 活动积温指标 $\left({ }^{\circ} \mathrm{C} \cdot \mathrm{d}\right)$

\begin{tabular}{|c|c|c|c|c|c|c|}
\hline 品种区 & 未种植区 & $\begin{array}{l}\text { 极早熟品种 } \\
\text { 种植区 }\end{array}$ & $\begin{array}{l}\text { 早熟品种种 } \\
\text { 植区 }\end{array}$ & $\begin{array}{l}\text { 中熟品种种 } \\
\text { 植区 }\end{array}$ & $\begin{array}{l}\text { 中晚熟品种 } \\
\text { 种植区 }\end{array}$ & $\begin{array}{l}\text { 晚熟品种种 } \\
\text { 植区 }\end{array}$ \\
\hline ACT10 & $<1800$ & $1800-2100$ & $2100-2400$ & $2400-2700$ & $2700-3000$ & $>3000$ \\
\hline
\end{tabular}




\section{2 冷害识别}

结合玉米不同发育阶段的三基点温度, 采用热量指数进行计算 ${ }^{[8]}$ 。选取出苗一七叶, 七叶-抽雄、抽雄-乳熟、乳熟-成熟 4 个阶 段平均热量指数作为玉米对环境热量状况 的响应指标, 出苗一抽雄期为玉米生长发育 前期, 抽雄-成熟期为后期。

$\mathrm{F}(\mathrm{T})=\left[\left(\mathrm{T}-T_{1}\right)\left(T_{2}-\mathrm{T}\right)^{B}\right] /\left[\left(T_{0}-\right.\right.$ $\left.T_{1}\right)\left(T_{2}-T_{0}\right)^{B}(1)$

$$
\mathrm{B}=\left(T_{2}-T_{0}\right) /\left(T_{0}-T_{1}\right)(2)
$$

$\mathrm{T}$ 表示逐日平均气温, $\mathrm{T}_{0} 、 \mathrm{~T}_{1} 、 \mathrm{~T}_{2}$ 分别 表示某一阶段适宜温度、下限温度及上限温 度。

参考玉米各发育阶段的最低、最高及适 宜温度 (郭建平, 2009), 计算玉米不同生 长阶段热量指数, 并采用热量指数距平百分 率作为冷害指数, 计算公式如下:

$$
\mathrm{CI}_{i}=\frac{F(T)_{i}-\bar{F}(T)}{\bar{F}(T)} \times 100 \%
$$

$\mathrm{CI}_{\mathrm{i}}$ 为 $\mathrm{i}$ 阶段冷害指数, $\bar{F}(T)$ 为该站 点历年热量指数平均值, $F(T)_{i}$ 为 $\mathrm{i}$ 阶段热量 指数。

研究采用蔡菁菁确定的冷害指标, 对各 站点冷害指数进行聚类分析, 并与历史冷害 年进行对比, 进行调整验证。将冷害等级划 分为无冷害 $\mathrm{CI}_{\mathrm{i}} \geq-2 \%$, 一般冷害 $-5 \% \leq \mathrm{CI}_{\mathrm{i}}<$ $-2 \%$, 严重冷害 $\mathrm{CI}_{\mathrm{i}}<-5 \%$ 。

\section{3 研究方法}

研究采用森斜率算法, 计算东北地区玉 米冷害指数的变化趋势。森斜率由 $\operatorname{sen}(1968 b)$ 提出, 是一种与 Mann-Kendall 检验发现的趋
势有关的非参数估算。它被定义为:

$\mathrm{B}=\operatorname{median} \frac{X i-X j}{T i-T j}$

其中 $X i$ 和 $X j$ 分别是时间 $\mathrm{Ti}$ 和 $\mathrm{T} \mathrm{j}$ 处的 数据值。

研究采用由芬兰气象研究所开发的 Makesens 1.0 进行数据估算 ${ }^{[9]}$ 。

\section{3. 结果与分析}

\section{1 玉米北扩影响分析}

过去 30 年热量条件改善, 导致东北三省 的玉米种植适宜区不断变化, 不同品种的玉 米种植北界呈现不同程度北移。如图 2 所示, 与 1980-1990 年代相比, 2000 年代春玉米早 熟品种种植北界向北移显著, 由嫩江一孙吴 向呼玛一黑河移动。中熟品种的安全种植区 域变动较大, 1980 年代吉林省中西部、黑龙 江南部地区主要适宜种植中熟品种玉米; 1990 年代吉林省中西部及三江平原的中熟 玉米区种植区逐渐被中晚熟品种取代, 中熟 品种主要适宜种植在松嫩平原地区; 2000 年 代中熟品种种植区向东部长白山区东缩及 黑龙江北扩。由于气候变暖, 使得中晚熟品 种的适宜种植区发生迅速扩展。1980 年代仅 辽宁省北部及黑龙江西南部较小区域适宜 种植中晚熟品种, 1990 年代吉林省西部地区 中晚熟品种种植区扩展, 2000 年代辽宁省北 部、吉林省中西部及黑龙江中南部的大部分 地区均适宜种植中晚熟品种玉米。辽宁省由 于纬度相对最低, 积温相对较高, 相对符合 晚熟品种对热量的高要求, 因此晚熟品种适 宜种植区主要在辽宁省北部地区呈现小范 围北扩。研究将气候变化背景下不同年代玉 米适宜种植区变动区域定义为敏感区。
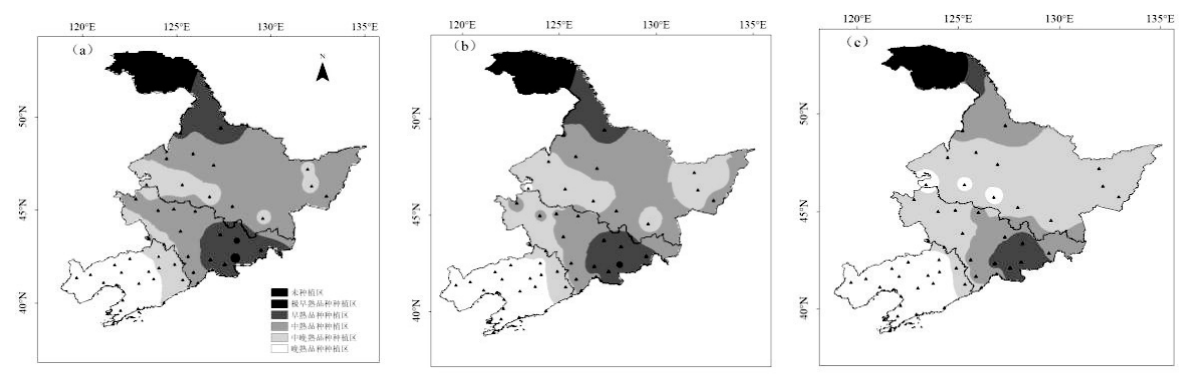

图 2 东北地区不同品种玉米安全种植区域（a）1980 年代（b）1990 年代（c）2000 年代 


\section{2 冷害频率演变特征}

根据东北不同玉米品种适宜种植区年代 变动情况, 绘制 1990 年代相较于 1980 年代 及 2000 年代相较于 1990 年代的变化区域, 即气候变化背景下东北地区玉米种植敏感 区 (图 3)。1990 年代较 1980 年代玉米种植 敏感区包括辽宁省北部地区、吉林省西部地 区及三江平原部分的地区; 2000 年代较 1990 年代玉米种植敏感区主要包括吉林省中东 部地区、黑龙江省中南大部分地区。近几年 东部玉米种植敏感区呈现北移东扩趋势。

结合玉米不同生育阶段的冷害指数计算 冷害频率变化率发现, 1990 年代相较 1980 年代冷害频率呈现大范围上升趋势, 而 2000 年代相较 1990 年代冷害频率表现大范围小 幅度下降趋势。1980 年代-1990 年代东北大 部分地区玉米生长后期冷害发生频率增长
显著, 以辽宁省北部吉林省西部地区一般冷 害的发生频率上升最为显著。辽宁省东南部 地区玉米生长后期的冷害发生频率呈现大 幅增加趋势, 可能与生长发育后期雨水增多 有关。吉林省中西部敏感地区生长发育后期 冷害频率呈现一定幅度的增加。研究表明玉 米受低温胁迫的生长阶段出现后延现象。 1990 年代-2000 年代东北大部分地区玉米冷 害发生频率出现下降趋势, 主要受全球气候 变暖影响显著。辽宁省西部地区一般冷害发 生频率出现小幅度上升趋势, 严重冷害发生 频率大范围下降, 而集安、临江等地区出现 后期严重冷害频率显著增加现象。说明全球 气候变暖背景下, 东北大部分地区冷害频率 呈现下降趋势, 冷害强度下降显著, 但是部 分地区一般冷害频率呈现小幅度上升且不 排除局地阶段性严重冷害发生的可能性。

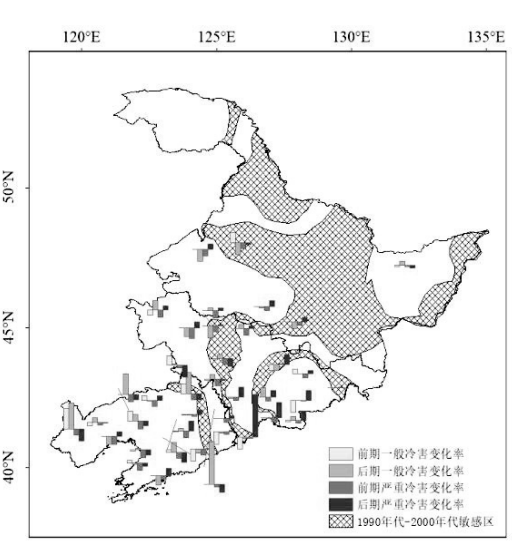

图 3 东北地区玉米敏感种植区及冷害频率变化

\section{3 冷害指数变化趋势}

对东北地区各站点作物不同生长期冷害 指数进行趋势分析。根据图 4 可以看出, 冷 害指数越小, 冷害发生的强度越高。 1980-2010 年东北地区玉米生长前期冷害指 数呈现微弱上升趋势。松嫩平原前期上升相 对显著, 说明冷害发生的强度趋势相对偏弱, 而辽宁省中南部、吉林省西部及三江平原北 部冷害指数上升趋势相对偏弱, 即冷害强度 呈现相对偏高趋势。1980-2010 年东北地区
玉米生长后期冷害指数森斜率存在正负, 辽 宁省、吉林省大部分地区及三江平原地区表 现为小幅度负值, 即冷害指数呈现下降趋势, 冷害强度提高。而黑龙江西北部地区玉米生 长后期冷害指数斜率为正值, 表现为冷害强 度下降趋势。综上, 玉米生长前期冷害指数 呈上升趋势, 后期大部分地区冷害指数呈现 小幅度下降趋势, 说明东北地区玉米在生长 后期易遭受低温胁迫发生冷害, 主要集中在 辽宁省南部地区、长白地区及三江平原北部 地区。 

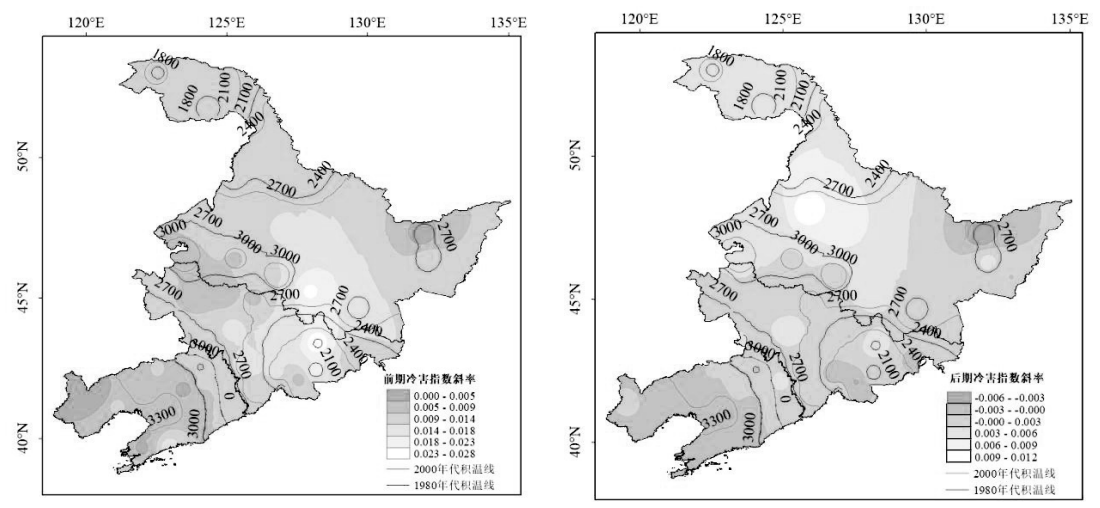

图 4.东北地区不同生长阶段冷害指数变化趋势

\section{4. 结论与讨论}

全球气候变暖导致作物所需热量条件改 善, 作物种植界限不断北扩, 品种孰制布局 发生变化。在过去 30 年内, 东北地区玉米 适宜种植区北扩显著, 早熟品种由嫩江一孙 吴向呼玛-黑河北移, 而 1980 年代-1990 年 代大部分地区适宜种植中熟品种, 到 2000 年代逐渐被中晚熟品种所替代, 晚熟品种界 线则主要在辽宁省北部地区小幅度北移。结 合作物生长阶段冷害判识发现, 东北地区玉 米在生长后期易遭受低温胁迫发生冷害, 主 要集中在辽宁省南部地区、长白地区及三江 平原北部地区。因此, 为了预防玉米种植区 北扩情况下冷害损失增大, 应该减少长白地 区、三江平原地区的玉米种植。

研究在一定程度上揭示了东北地区玉米 种植区域北扩空间位移及位移之后敏感区 表述, 从玉米生长阶段出发, 阐述了气候变 化背景下冷害发生演变规律。但是, 由于气 象站点的缺乏, 导致敏感区及非敏感区的冷 害区别不明显。因此, 未来在进行相关研究 时需要尽可能实现气象要素的均匀分布, 从 而提高分析问题的精度。

\section{Acknowledgments}

This research is supported by the Supported by the National Science Foundation of China (41571491 and 41371495); The China Special Fund for Meteorological Research in the Public Interest (GYHY201506001-6); The National Key Technology R\&D Program of China under Grant (2013BAK05B01); The
Fundamental Research Funds for the Central Universities of China (2412016KJ046).

\section{致谢}

本研究得到了国家自然科学基金项目 （41571491 和 41371495)、公益性行业（气 象）科研重大专项 (GYHY201506001-6)、国 家重点技术研发项目（2013BAK05B01）、中 央高校基本科研业务费专项资金资助 (2412016KJ046)

\section{参考文献}

[1] 李勇, 杨晓光, 王文峰, 陈阜. 全球气候 变暖对中国种植制度可能影响 V.气候 变暖对中国热带作物种植北界和寒害 风险的影响分析中国农业科学, 2010, 4 3 (12) : 2477-2484.

[2] 赵锦, 杨晓光, 刘志娟, 吕硕, 王静, 陈阜. 全球气候变暖对中国种植制度的可能 影响 X. 气候变化对东北三省春玉米气 候适宜性的影响. 中国农业科学, 2014, 47 (16) : 3143-3156.

[3] 杨晓光, 刘志娟, 陈阜. 全球气候变暖对 中国种植制度可能影响: VI. 未来气候 变化对中国种植制度北界的可能影响. 中国农业科学, 2011, 44 (08) : 1562-157 0 .

[4] 赵俊芳, 杨晓光, 刘志娟. 气候变暖对东 北三省春玉米严重低温冷害及种植布 局的影响. 生态学报, 2009, 29 (12):654 4-6551.

[5] Guo C, Zhu M, Cao T, et al. Easter n Jilin Province Rice Cold Damage Ri 
sk Vulnerability Curve Established Bas ed on CERES-Rice Model. The 7th A nnual Meeting of Risk Analysis Counc il of China Association for Disaster Pr evention. 2016,11(600-605).

[6] Wang R, Liu X, Zhang J, et al. Hazar d Analysis of Drought and Flood Disa ster for Maize in Xiliaohe Watershed.

The 7th Annual Meeting of Risk Anal ysis Council of China Association for Disaster Prevention. 2016,11(606-611).

[7] Zhao J, Yang X, Lv S, et al. Variability of available climate resources and disaster risks for different maturity types of spring maize in Northeast China. Regional Environmental Change, 2014, 14(1):7-26.

[8] 高晓容, 王春乙, 张继权. 东北玉米低温 冷害时空分布与多时间尺度变化规律 分析. 灾害学, 2012, 27 (04) :65-70.

[9] Santos M, Fragoso M. Precipitation va riability in Northern Portugal: Data ho mogeneity assessment and trends in ex treme precipitation indices. Atmospheri c Research, 2013, 131(5):34-45. 